\title{
Prolonged Contraction Duration in Aged Myocardium
}

\author{
Edward G. Lakatta, Gary Gerstenblith, Charles S. Angell, \\ Nathan W. Shock, and Myron L. Weisfeldt \\ From the Gerontology Research Center, National Institute of Child Health and \\ Human Development, National Institutes of Health, Baltimore, Maryland \\ 21224, and the Department of Medicine, Johns Hopkins University School of \\ Medicine and Hospital, Baltimore, Maryland 21205
}

\begin{abstract}
A в S T R A C T Isometric performance at $29^{\circ} \mathrm{C}$ was measured in left ventricular trabeculae carneae from young adult (6-mo) and aged (25-mo) rats $(n=18$ in each group). Active tension and maximal rate of tension development did not differ with age, but contraction duration was $255 \pm 6 \mathrm{~ms}$ in the young adult and $283 \pm 6 \mathrm{~ms}$ in the aged group $(P<0.001)$. Although catecholamine content per gram heart weight was less in the aged myocardium, additional experiments showed that neither $1 \times 10^{-8} \mathrm{M}$ propranolol nor pretreatment with 6-hydroxydopamine eliminated the age difference in contraction duration. To determine if this age difference resulted from a prolonged active state, electromechanical dissociation and the overshoot of contraction duration during recovery from hypoxia were measured. During paired stimulation greater mechanical refractoriness was found in aged muscles $(P<0.01)$, but intracellular action potential recordings showed no age difference in the electrical refractory period. On recovery from hypoxia, contraction duration overshoot was $117 \pm 4 \%$ of control in the young and $138 \pm 4 \%$ of control in the aged muscles $(P<0.01)$. The greater electromechanical dissociation and greater overshoot in contraction duration following hypoxia in aged myocardium suggests that prolonged contraction duration in aged myocardium results from a prolonged active state rather than changes in passive properties or myocardial catecholamine content.
\end{abstract}

\section{INTRODUCTION}

While the ability of isolated mammalian myocardium to develop force under isometric conditions appears to be unaltered with age (1-3), prolonged contraction duration

Dr. Weisfeldt is an Established Investigator of the American Heart Association.

Received for publication 21 June 1974.
$(\mathrm{CD})^{1}$ in aged myocardium has been demonstrated by some investigators $(1,2)$. This prolongation is reflected as either prolonged time to peak tension $(1,2)$, prolonged relaxation time (1), or both (1). Prolonged $\mathrm{CD}$ could result from changes in myocardial passive properties, active properties, or both. Studies using indirect polygraphic techniques have found that isovolumic contraction and relaxation are prolonged in aged man and it has been been postulated that this is due to age differences in passive visco-elastic properties (4). Alternatively, age differences in active properties, possibly resulting from decreased catecholamine levels in aged myocardium $(5,6)$, may also account for prolongation of CD. This mechanism is suggested by the facts that catecholamines shorten the duration of active state (7) and that catecholamine depletion with reserpine prolongs $\mathrm{CD}$ (8).

The present study confirmed that under isometric conditions $C D$ is prolonged in isolated aged rat myocardium. Additional experiments were then undertaken to investigate whether this age-related change results from a prolongation of active state and whether this change is mediated by myocardial catecholamine content. The timecourse of active state has been characterized by measurements of electromechanical dissociation during paired stimulation (9) and of CD overshoot above baseline during recovery from hypoxia (10-12). Therefore, electromechanical dissociation, defined as mechanical refractoriness in the absence of electrical refractoriness (9), and the overshoot in $\mathrm{CD}$ during recovery from hypoxia were

\footnotetext{
${ }^{1}$ Abbreviations used in this paper: AT, active isometric tension; $\mathrm{CD}$, contraction duration; CSA, cross-sectional area; $\mathrm{d} F / \mathrm{d} t$, the first derivative of force with respect to time; $\mathrm{d} T / \mathrm{d} t$, maximal rate of tension development; $\mathrm{L}_{\mathrm{Max}}$, length at which active tension is maximal; $R T$, resting tension; $\mathrm{RT}_{\frac{1}{2}}$ (half-relaxation time), time for tension to fall to $50 \%$ of its peak value; TCA, trichloroacetic acid; $\mathrm{TPT}$, time to peak tension.
} 
measured in young adult and aged myocardium. To determine if the age-associated prolongation of $\mathrm{CD}$ results from a catecholamine-mediated or from a more intrinsic change in active state, additional experiments were performed in which $C D$ was measured in the presence of propranolol and after tissue catecholamine depletion by pretreatment with 6-hydroxydopamine.

\section{METHODS}

Male, nonbreeder, Wistar rats, aged 6-, 12-, and 25-mo, were selected from the Gerontology Research Center aging colony. 6-mo of age, as body weight begins to plateau, is considered young adulthood, 12-mo of age is considered middle age, and 25-mo of age, when approximately $50 \%$ colony mortality occurs, is considered senescence (13). Previous studies of animals from this colony have failed to detect evidence of specific cardiovascular disease or hypertension, in either the middle-aged or the aged rat (14). The aged heart weighs more, the cavity is larger, and estimated wall thickness is the same in the middle-aged and aged heart $(15,16)$. The connective tissue constitutes $3.5 \%$ more of the endocardial tissue in the aged than in the middle-aged animals (1). Studies of cardiac performance revealed that there is no significant age change in the ability to extract oxygen under normal and hypoxic conditions (17), or in the ability to respond to an acute volume load (16). However the response to an acute pressure load was less in the aged rat (16).

In the present study, hearts were removed under light ether anesthesia and immediately immersed in iced oxygenated modified Krebs-Ringer solution. The heart was then slit, laid flat, and a trabecular muscle from the posterior ventricular wall was removed. At $\mathrm{L}_{\mathrm{Max}}$, the length at which active tension is maximal, the trabecular cross-sectional area (CSA) averaged less than $0.9 \mathrm{~mm}^{2}$ and the length averaged $5.5 \mathrm{~mm}$ (Table I). Cross-sectional area was determined as previously described (1). The muscle was suspended between two spring-loaded Lucite clamps, which had been roughened to avoid slippage, inside a waterjacketed chamber at $29^{\circ} \mathrm{C}$. The chamber was bathed with a Krebs-Ringer bicarbonate solution (18) modified by decreasing the $\mathrm{CaCl}_{2}$ to $1.0 \mathrm{mM}$, the $\mathrm{MgSO}_{4}$ to $0.6 \mathrm{mM}$, and by adding glucose to a final concentration of $16 \mathrm{mM}$. The solution was oxygenated both in the reservoir and directly in the muscle chamber with a mixture of $95 \%$ oxygen-5\% carbon dioxide resulting in a $\mathrm{Po}_{2}$ of approximately $680 \mathrm{~mm}$ $\mathrm{Hg}$ and $\mathrm{a} \mathrm{pH}$ of 7.45. The volume of the muscle chamber was $17 \mathrm{~cm}^{3}$ and the chamber perfusion rate was $13 \mathrm{~cm}^{3} /$ min with no recirculation. The muscles were stimulated at a rate of 24 beats per min with a Grass stimulator (model SD9, Grass Instrument Co., Quincy, Mass.) via platinum field electrodes. Voltage was $20 \%$ above threshold and duration of stimulus was $5 \mathrm{~ms}$. Under these conditions, the muscles exhibited stable performance for at least 4-5 h as has been demonstrated previously (19). Muscle length was varied by raising or lowering a lever to which the bottom muscle clamp was firmly attached by a thin rod. The gear mechanism was calibrated to change length in $0.01-\mathrm{mm}$ increments. The upper clamp was fixed to a thin rod which was attached to a force transducer (Hewlett-Packard Co., Waltham, Mass.), which gave a linear response over the range of $0.1-10 \mathrm{~g}$ of force. The compliance of the entire apparatus was $0.007 \mathrm{~mm} / \mathrm{g}$ force between 0 and $10 \mathrm{~g}$ of force. The first derivative of force, $(\mathrm{d} F / \mathrm{d} t)$, was obtained by using a Hewlett-Packard preamplifier model $8805 \mathrm{~B}$.
Force, $\mathrm{d} F / \mathrm{d} t$, and stimulus artifact were recorded on a Hewlett Packard ink writing polygraph, model 7888A, at a speed of $100 \mathrm{~mm} / \mathrm{s}$.

Experimental procedure. Two muscles, each of different age, were studied simultaneously on a given day. During an initial 90-min equilibration period, resting force was maintained at approximately $1 \mathrm{~g}$. The muscle was then stretched to $L_{\text {Max }}$ and allowed to equilibrate for an additional $60 \mathrm{~min}$. The following base-line parameters were then measured: resting force, peak active isometric force, and maximal rate of force development. Force measurements were normalized to tension by dividing by the cross-sectional area and the results expressed as resting tension (RT), peak active isometric tension (AT), and maximal rate of tension development $(\mathrm{d} T / \mathrm{d} t)$. The time to peak tension (TPT) was measured as the time from onset of active tension to peak active tension and the half-relaxation time $\left(\mathrm{RT}_{\frac{1}{2}}\right)$ was measured as the time for tension to fall to $50 \%$ of its peak value. The sum of TPT and $\mathrm{RT}_{\frac{1}{3}}$ was used as contraction duration (CD). After base-line stabilization, one group of these muscle underwent paired stimulation to determine mechanical refractoriness and subsequent hypoxia and reoxygenation to determine $\mathrm{CD}$ overshoot during recovery from hypoxia. A second group of muscles was exposed to propranolol and CD was remeasured.

Mechanical refractoriness. Paired stimulation was performed on trabeculae which were paced at the rate of 24 beats/min. A second stimulus was introduced at decreasing intervals after the initial stimulus. The interstimulus interval was shortened in a stepwise fashion from 400 to $80 \mathrm{~ms}$. A second mechanical event was defined as either a discrete second twitch, which if present was easily discernable from the $\mathrm{d} F / \mathrm{d} t$ tracing, or as an increase in $\mathrm{RT}_{\frac{1}{2}}$ following the second stimulus (20).

Hypoxia and reoxygenation. Hypoxia was induced by abruptly changing to a bathing fluid equilibrated with $95 \%$ $\mathrm{N}_{2}-5 \% \quad \mathrm{CO}_{2}$. The chamber was also bubbled with $95 \% \mathrm{~N}_{2-}$ $5 \% \quad \mathrm{CO}_{2}$ and the entire transition was accomplished in approximately $5 \mathrm{~s}$. The $\mathrm{Po}_{2}$ fell progressively and after 8 min was approximately $20 \mathrm{~mm} \mathrm{Hg}$ until the termination of the 20-min hypoxic period. Reoxygenation was accomplished by reversing the above sequence and after $1 \mathrm{~min}$ of reoxygenation $\mathrm{PO}_{2}$ had increased to the base-line value of $680 \mathrm{~mm} \mathrm{Hg}$.

Propranolol. In preliminary experiments, it was determined that $1 \times 10^{-6} \mathrm{M} d l$-propranolol was able to reduce the response to exogenous $1 \times 10^{-6} \mathrm{M}$ norepinephrine by $50 \%$. In the second group of muscles, $d l$-propranolol, was continuously added to the bathing fluid to result in a concentration of $1 \times 10^{-8} \mathrm{M}$. After $20 \mathrm{~min}$ of exposure, the parameters of the isometric twitch were remeasured.

Electrical refractory period. In a third group of muscles the action potential of a ventricular muscle cell was recorded by an impaled microelectrode while the muscle fiber was stimulated by extracellular electrodes at a rate of 24 beats/min under conditions identical to those described above. The duration of the action potential at $80 \%$ repolarization was measured. The electrical effective refractory period was then measured by delivering a second stimulus at progressively shorter intervals until a conducted action potential was no longer recorded (21).

6-Hydroxydopamine. A fourth group of rats was pretreated with 6-hydroxydopamine, $20 \mathrm{mg} / \mathrm{kg}$, administered subcutaneously $24-48 \mathrm{~h}$ before the experiment, in the manner described by Roberts (22). This dose effected an average catecholamine depletion of $95 \%$ of control in the young adult animals and $97 \%$ of control in the aged animals. 
TABLE I

Base-line Performance

\begin{tabular}{|c|c|c|c|c|c|c|c|c|c|}
\hline Age & No. & CSA & Length & RT & AT & $\mathrm{d} T / \mathrm{d} t$ & TPT & $R T \frac{1}{2}$ & $\mathrm{CD}$ \\
\hline$m o$ & & $m m^{2}$ & $m m$ & $\mathrm{~g} / \mathrm{mm}^{2}$ & $\mathrm{~g} / \mathrm{mm}^{2}$ & $\mathrm{~g} / \mathrm{mm}^{2} / \mathrm{s}$ & $m s$ & $m s$ & $m s$ \\
\hline 6 & 18 & $0.90 \pm 0.06$ & $5.22 \pm 0.28$ & $1.36 \pm 0.15$ & $2.92 \pm 0.22$ & $34.8 \pm 2.8$ & $134 \pm 2.2^{*}$ & $121 \pm 4.2^{*}$ & $255 \pm 6.1 \ddagger$ \\
\hline 12 & 8 & $0.81 \pm 0.11$ & $5.25 \pm 0.61$ & $1.36 \pm 0.21$ & $2.85 \pm 0.22$ & $36.1 \pm 2.2$ & $134 \pm 4.5$ & $118 \pm 6.9 \S$ & $252 \pm 10.7 \S$ \\
\hline 25 & 18 & $0.84 \pm 0.07$ & $5.71 \pm 0.36$ & $1.45 \pm 0.18$ & $3.40 \pm 0.26$ & $38.8 \pm 3.6$ & $142 \pm 2.0$ & $141 \pm 5.0$ & $283 \pm 6.2$ \\
\hline
\end{tabular}

${ }^{*} P<0.01$ vs. 25 mo.

$\ddagger P<0.001$ vs. $25 \mathrm{mo}$.

$\S P<0.05$ vs. 25 mo.

Control values for myocardial catecholamines in each age group are presented below. The same base-line parameters of isometric performance were measured in this group and these muscles subsequently underwent hypoxia and reoxygenation.

Catecholamine assay. A fifth group of rats were decapitated and the hearts were quickly removed, rinsed in iced saline, blotted, weighed, and then rapidly frozen in liquid nitrogen. The heart was then pulverized, blended with $5 \%$ trichloracetic acid (TCA), centrifuged, and filtered. An aliquot of the TCA filtrate, or of standard catecholamine solution, was combined with disodium EDTA and the $\mathrm{pH}$ was adjusted to 6.5. Catecholamines were isolated on prefilled Bio-Rad ion exchange columns (Bio-Rad Laboratories, Richmond, Calif.), eluted with sodium hydroxide, and analyzed by a fluorometric procedure using a modified trihydroxyindole method (23). Recovery of standard solution of catecholamine added to the column was $97 \pm 1 \%$ and recovery of catecholamines added to tissue homogenates in the range of $0.5-1.01 \mu \mathrm{g} /$ heart was $91 \pm 4 \%$.

Except as indicated results are expressed as mean \pm standard error and compared by using Student's $t$ test for nonpaired values (24).

\section{RESULTS}

Base-line mechanical performance. The base-line mechanical data from all trabeculae except those from hearts which had been depleted of catecholamine by 6-hydroxydopamine are presented in Table I. There was no significant age difference in mean cross-sectional area or muscle length at Lmax. There was also no significant age difference in $\mathrm{RT}, \mathrm{AT}$, or $\mathrm{d} T / \mathrm{d} t$. However TPT, RT, and CD were significantly prolonged in the 25-mo age group. The $\mathrm{CD}$ in the aged group was $11 \%$ longer than in the 6-mo group and $12 \%$ longer than in the 12-mo group.

Mechanical refractoriness. Fig. 1 depicts the percent of muscres in each age group exhibiting a second mechanical event at each coupling interval. At long coupling intervals (400-300 ms) all muscles responded. As the coupling interval decreased, significantly fewer aged than young adult muscles exhibited a second mechanical response $\left(P<0.01\left[\mathrm{X}^{2}\right]\right)$. Fig. 2 shows the typical responses of an aged and young adult muscle at coupling intervals from 400 to $120 \mathrm{~ms}$.

Hypoxia and reoxygenation. The effect of hypoxia and reoxygenation was examined in muscles from 6-, 12-, and 25-mo-old rats. AT, $\mathrm{d} T / \mathrm{d} t$, and $\mathrm{CD}$ expressed as percent of control shortened proportionately in all three age groups after $20 \mathrm{~min}$ of hypoxia (Table II). $2 \mathrm{~min}$ after reoxygenation, the overshoot above baseline in $\mathrm{CD}$ was significantly greater in the old muscles. Fig. 3 illustrates the change in $\mathrm{CD}$ expressed as percent control during the entire hypoxia and reoxygenation sequence. The 12-mo group was not different from the 6-mo group and has been omitted from the chart for clarity. It can be seen that $C D$ shortens during hypoxia and overshoots during early reoxygenation before returning towards control values at $15 \mathrm{~min}$. The age differences in overshoot prolongation of CD is maximal during early reoxygenation and diminishes with time.

Electrical refractory period. The action potential duration at $80 \%$ repolarization was $73.8 \pm 6.0 \mathrm{~ms}$ in the 6 -mo, $n=10$, and $76.0 \pm 5.8 \mathrm{~ms}$ in the $25-\mathrm{mo}$ age group, $n=10$ (NS).

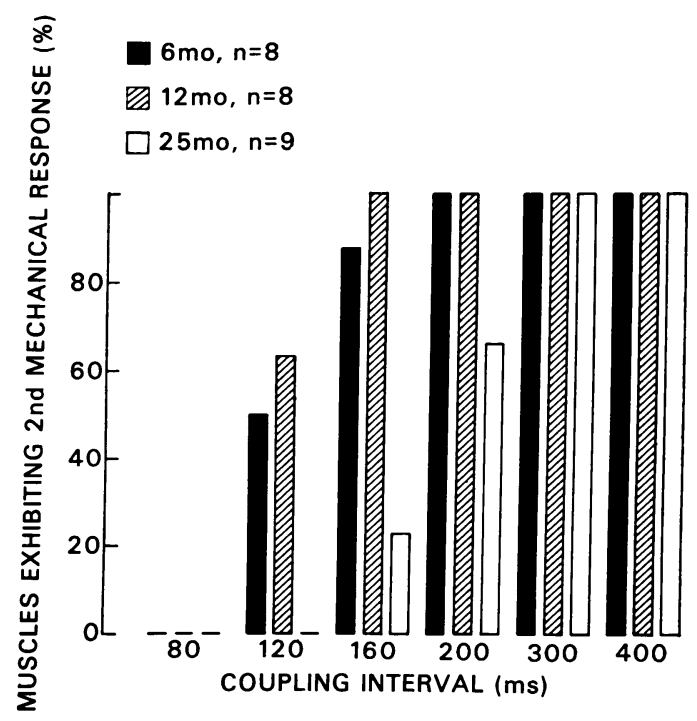

FIGURE 1 Effect of age on the ability of muscles to respond to a second stimulus during paired pacing at varied coupling intervals. As the coupling interval shortens fewer muscles in the aged group exhibit a second mechanical response, $\left(P<0.01\left[\mathrm{X}^{2}\right]\right)$. 

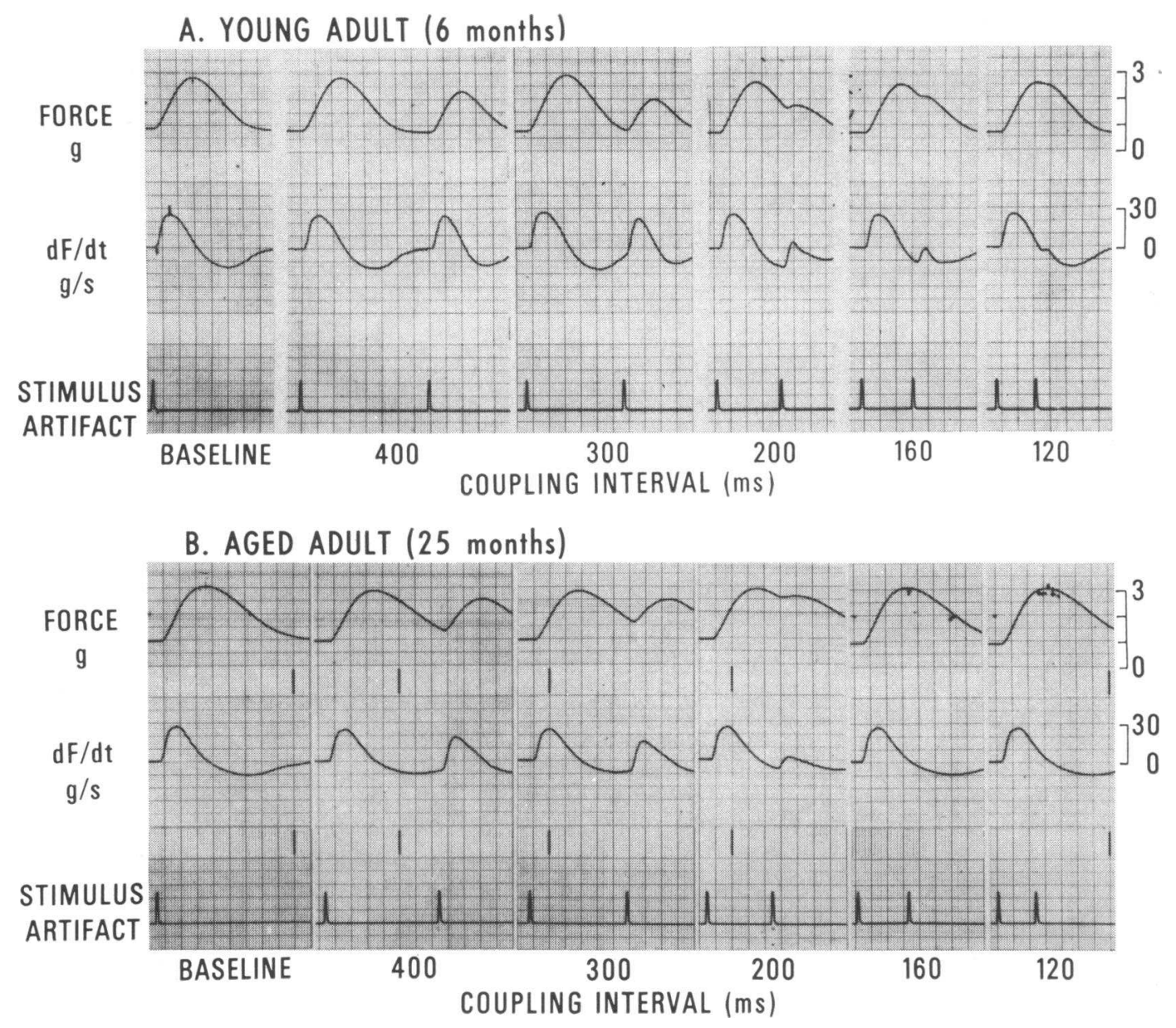

FIGURE 2 Comparison of the response of a typical young adult (panel A) and aged (panel B) muscle to paired pacing at varied coupling intervals. The muscle from the young adult rat exhibited a second mechanical response evident in both the force and $\mathrm{d} F / \mathrm{d} t$ tracings at coupling intervals from 400 to $120 \mathrm{~ms}$ inclusive. The muscle from the aged rat did not generate a second mechanical response at coupling intervals of $160 \mathrm{~ms}$ or less.

The electrical effective refractory period was $83.3 \pm$ $5.6 \mathrm{~ms}$ in the 6-mo-old group, $n=9$, and $86.5 \pm 5.4 \mathrm{~ms}$ in the 25-mo-old group, $n=10$. Failure of all muscles to generate a second mechanical response at the $80-\mathrm{ms}$ coupling interval, as seen in Fig. 1, probably represents electrical refractoriness.

Relation of catecholamines to $C D$ with age. The catecholamine content per gram wet heart weight was significantly less in the 25-mo group than in the 6- or 12-mo groups (Table III). This decrease in content per gram heart weight is in part attributable to a greater heart weight in the old rat.

$\mathrm{CD}$ and other parameters of isometric contraction were examined before and after exposure to propranolol in muscles from nine 6- and nine 25-mol-old rats (Table IV). Although propranolol tended to decrease CD in each age group, the prolongation of $\mathrm{CD}$ persisted in the aged group.

Nine muscles from 6-mo and nine muscles from 25-moold rats were studied after depletion of tissue catecholamines with 6-hydroxydopamine (Table V). Although $\mathrm{CD}$ tended to increase in both age groups (NS), the age-associated prolongation of $\mathrm{CD}$ was not obliterated. After 6-hydroxydopamine pretreatment in the aged muscles, $\mathrm{d} T / \mathrm{d} t$ was less and TPT was greater when compared to the aged muscles in the control group in Table I $(P<0.05)$. Similar differences did not occur in the young muscles after 6-hydroxydopamine.

After $20 \mathrm{~min}$ of hypoxia $\mathrm{d} T / \mathrm{d} t$ fell to a similar extent in both groups; AT fell less in the aged than in the young group and was accompanied by less shortening of CD (Table VI). After $2 \mathrm{~min}$ of reoxygenation the 
overshoot in $\mathrm{CD}$ above baseline was, as in the noncatecholamine-depleted muscles, significantly greater in the old group and again represented significantly greater overshoot in both TPT and RT.

\section{DISCUSSION}

This study demonstrates that $\mathrm{CD}$ is prolonged in aged myocardium and confirms previous observations $(1,2)$. Since CD did not vary between 6 and $12 \mathrm{mo}$, prolongation of $C D$ represents a phenomenon of late adulthood. Since appreciable variation in $\mathrm{CD}$ occurs within age groups, a substantial number of muscles must be studied to demonstrate a significant age difference. The failure of some investigators (3) to find this difference may be explained by a small sample size. Our findings that $\mathrm{RT}, \mathrm{AT}$, and $\mathrm{d} T / \mathrm{d} t$ do not change with age are consistent with the results of previous studies (1-3).

Prolonged $C D$ could result from age changes in the active state, visco-elasticity, or both. The measurements of mechanical and electrical refractoriness and those of CD overshoot during reoxygenation suggest that prolonged $C D$ in the aged myocardium is due to an ageassociated prolongation of active state. During paired stimulation experiments with short coupling intervals fewer old than young muscles were able to respond with a second mechanical event. Since the electrical effective refractory period is unchanged with age, the greater mechanical refractoriness indicates greater electomechanical dissociation in the old muscles (9) and therefore a change in active properties of aged myocardium. The overshoot in $C D$ during recovery from hypoxia has been ascribed to a prolongation of active state (10-12) and the greater overshoot in old myo-

TABLE II

Hypoxia and Reoxygenation

\begin{tabular}{ccccc}
\hline Age & No. & $\mathrm{AT}$ & $\mathrm{d} T / \mathrm{d} t$ & $\mathrm{CD}$ \\
\hline$m o$ & & $g / \mathrm{mm}^{2}$ & $\mathrm{~g} / \mathrm{mm}^{2} / \mathrm{s}$ & $m s$ \\
Control & & & & \\
6 & 9 & $2.78 \pm 0.38$ & $34.4 \pm 4.3$ & $254.2 \pm 10.39$ \\
12 & 8 & $2.85 \pm 0.22$ & $36.1 \pm 2.2$ & $251.6 \pm 10.67$ \\
25 & 9 & $3.54 \pm 0.41$ & $42.7 \pm 5.0$ & $282.0 \pm 9.99$
\end{tabular}

$\%$ Control hypoxia $(20 \mathrm{~min})$

$\begin{array}{rrrrr}6 & 9 & 35.9 \pm 1.70 & 48.1 \pm 1.98 & 81.3 \pm 2.66 \\ 12 & 8 & 33.2 \pm 2.83 & 43.2 \pm 3.09 & 79.48 \pm 1.49 \\ 25 & 9 & 35.5 \pm 2.54 & 40.9 \pm 3.32 & 83.50 \pm 1.81\end{array}$

$\%$ Control reoxygenation $(2 \mathrm{~min})$

$\begin{array}{rrrrl}6 & 9 & 78.3 \pm 6.71 & 69.4 \pm 4.75 & 117.6 \pm 3.70^{*} \\ 12 & 8 & 73.0 \pm 7.16 & 63.5 \pm 5.84 & 122.1 \pm 3.67 \ddagger \\ 25 & 9 & 84.6 \pm 5.63 & 69.3 \pm 4.91 & 138.1 \pm 4.47\end{array}$

${ }^{*} P<0.01$ vs. 25 mo.

$\ddagger P<0.05$ vs. 25 mo.

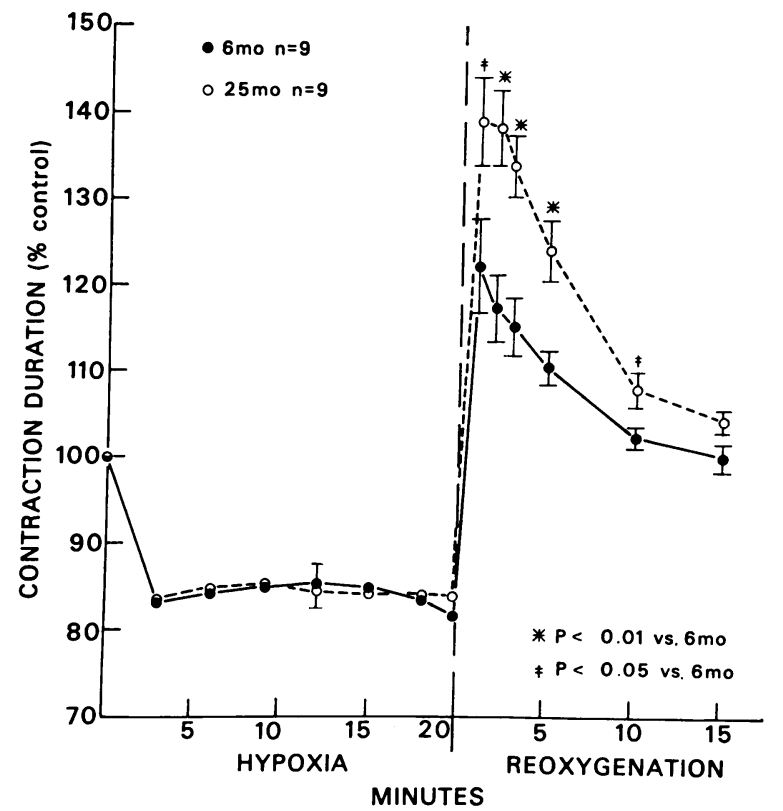

Figure 3 Effect of age on CD expressed as percent control during hypoxia and reoxygenation. During reoxygenation, the $C D$ overshoot above baseline is greater in the aged myocardium. Base-line data is given in Table II.

cardium would therefore appear to result from a greater prolongation of active state.

Alternatively, if prolonged $C D$ in the aged myocardium is explained solely on the basis of a change in visco-elasticity, stiffness would have to be decreased. But such a muscle would generate less active tension and active tension does not decerase with age. In addition, it has been demonstrated that although stiffness increases during hypoxia it decreases towards baseline without an overshoot during reoxygenation $(25,26)$. Therefore, the overshoot prolongation of $\mathrm{CD}$ during reoxygenation cannot be explained by a change in stiffness properties. Furthermore, any age difference in recovery rate of stiffness would necessitate an age difference in recovery rate of tension development and there was none. Therefore, prolonged $\mathrm{CD}$ in aged myocardium must involve

TABLE III

Myocardial Catecholamine Content

\begin{tabular}{rcccc}
\hline Age & No. & $\begin{array}{c}\text { Total } \\
\text { catecholamine }\end{array}$ & Heart wt & Catecholamine \\
\hline$m o$ & & $\mu g /$ heart & $g$ & $\mu g / g$ heart wt \\
6 & 10 & $0.693 \pm 0.057$ & $1.27 \pm 0.022^{*}$ & $0.569 \pm 0.063^{*}$ \\
12 & 11 & $0.687 \pm 0.040$ & $1.50 \pm 0.087$ & $0.474 \pm 0.040 \ddagger$ \\
25 & 10 & $0.555 \pm 0.061$ & $1.73 \pm 0.097$ & $0.325 \pm 0.037$ \\
\hline
\end{tabular}

${ }^{*} P<0.01$ vs. 25 mo.

$\ddagger P<0.05$ vs. 25 mo. 
TABLE IV

Effect of Propranolol on Isometric Contraction

\begin{tabular}{|c|c|c|c|c|c|c|}
\hline Age & No. & AT & $\mathrm{d} T / \mathrm{d} t$ & TPT & RT $\frac{1}{2}$ & $\mathrm{CD}$ \\
\hline mo & & $\mathrm{g} / \mathrm{mm}^{2}$ & $\mathrm{~g} / \mathrm{mm}^{2} / \mathrm{s}$ & $m s$ & $m s$ & $m s$ \\
\hline \multicolumn{7}{|c|}{ Prepropranolol } \\
\hline 6 & 9 & $3.06 \pm 0.24$ & $35.4 \pm 4.0$ & $133 \pm 3.5^{*}$ & $123 \pm 3.9^{*}$ & $256 \pm 6.9^{*}$ \\
\hline 25 & 9 & $3.26 \pm 0.34$ & $34.9 \pm 4.9$ & $142 \pm 1.9$ & $141 \pm 7.1$ & $284 \pm 7.7$ \\
\hline \multicolumn{7}{|c|}{ Postpropranolol } \\
\hline 6 & 9 & $2.89 \pm 0.24$ & $34.7 \pm 3.8$ & $129 \pm 2.6 \ddagger$ & $118 \pm 4.8^{*}$ & $248 \pm 5.4 \ddagger$ \\
\hline 25 & 9 & $3.12 \pm 0.34$ & $33.7 \pm 4.8$ & $140 \pm 2.1$ & $137 \pm 7.0$ & $277 \pm 7.6$ \\
\hline
\end{tabular}

$* P<0.05$ vs. $25 \mathrm{mo}$.

$\ddagger P<0.01$ vs. $25 \mathrm{mo}$.

prolonged active state and not just a change in viscoelasticity. It is possible that changes in visco-elasticity occur concurrently with this change in active state.

Depletion of endogenous catecholamines increases CD without affecting the length-tension curve (12). It is also known that catecholamines are liberated from heart muscle during hypoxia (27) and reoxygenation (28) and therefore may modify recovery from hypoxia (29, 30 ). Since myocardial catecholamine content per gram heart weight in our study as well as others $(5,6)$ decreased significantly over the same age range in which CD increased, an attractive hypothesis might be that diminished catecholamine levels in aged myocardium causes the prolonged active state. Although catecholamine depletion with 6-hydroxydopamine tended to prolong $\mathrm{CD}$, the age difference persisted and therefore cannot be explained by changes in tissue catecholamine content. Furthermore, the age difference in overshoot of CD during recovery from hypoxia persisted after catecholamine depletion with 6-hydroxydopamine and hence cannot be explained by a catecholamine mechanism. Propranolol likewise did not obliterate the age change in $\mathrm{CD}$. Therefore it appears that increased duration of active state in aged myocardium results not from a catecholamine-mediated change in active state but from a more intrinsic alteration. However, unlike 6-hydroxydopamine, propranolol tended to decrease $\mathrm{CD}$ in both groups as well as to decrease AT and $\mathrm{d} T / \mathrm{d} t$. Although propranolol was employed because of its beta blocking properties, it is apparent that its direct negative inotropic effect $(31,32)$ predominated.

The duration of active state is thought to be determined by the length of time calcium is present on the contractile proteins and reflects a balance between the time-course of calcium delivery onto and the time-course of calcium removal from the contractile proteins (33). Prolonged duration of active state in old myocardiun can theoretically result from prolonged calcium delivery to or slower calcium removal from the contractile proteins or both. In other mammalian species it has been postulated that changes in the transmembrane delivery of electrogenic calcium are influenced by the duration of the phase two plateau of the action potential (34). There is no distinct plateau in rat myocardial action potential but insofar as action potential duration may reflect this movement it appears that there is no age difference. Release from intracellular sites may play a more important role in the delivery of calcium to the contractile proteins (35). However, electromechanical dissociation at short coupling intervals would not result from prolonged delivery of calcium from intracellular sites to the contractile proteins but results rather from inadequate time to recharge the releasing site with calcium (9). Inadequate time to recharge these sites could be due to delayed calcium removal from the contractile protein or to delayed translocation of calcium from

TABLE V

Base-line Performance after 6-Hydroxydopamine Pretreatment

\begin{tabular}{rccccccccc}
\hline Age & No. & CSA & Length & RT & AT & $\mathrm{d} T / \mathrm{d} t$ & TPT & RT & CD \\
\hline$m o$ & & $m m^{2}$ & $m m$ & $g / m^{2}$ & $g / m^{2}$ & $g / m^{2} / s$ & $m s$ & $m s$ & $m s$ \\
6 & 9 & $0.85 \pm 0.06$ & $6.33 \pm 0.41$ & $1.44 \pm 0.19$ & $3.15 \pm 0.35$ & $34.7 \pm 3.3$ & $140 \pm 2.5^{*}$ & $133 \pm 6.4$ & $270 \pm 8.4 \ddagger$ \\
25 & 9 & $0.75 \pm 0.06$ & $6.85 \pm 0.57$ & $1.41 \pm 0.13$ & $2.66 \pm 0.29$ & $27.8 \pm 3.0$ & $156 \pm 5.0$ & $143 \pm 6.5$ & $299 \pm 10.9$ \\
\hline
\end{tabular}

* $P<0.01$ vs. $25 \mathrm{mo}$.

$\ddagger P<0.05$ vs. 25 mo. 
TABLE VI

Hypoxia and Reoxygenation after 6-Hydroxydopamine Pretreatment

\begin{tabular}{|c|c|c|c|c|}
\hline Age & No. & AT & $\mathrm{d} T / \mathrm{d} t$ & $\mathrm{CD}$ \\
\hline mo & & $\mathrm{g} / \mathrm{m} \mathrm{m}^{2}$ & $\mathrm{~g} / \mathrm{mm}^{2} / \mathrm{s}$ & $m s$ \\
\hline \multicolumn{5}{|c|}{$\%$ Control hypoxia (20 min) } \\
\hline $\begin{array}{r}6 \\
25\end{array}$ & $\begin{array}{l}9 \\
9\end{array}$ & $\begin{array}{l}31.96 \pm 1.47^{*} \\
37.10 \pm 1.91\end{array}$ & $\begin{array}{l}43.98 \pm 1.88 \\
45.40 \pm 1.34\end{array}$ & $\begin{array}{l}78.38 \pm 1.41 \ddagger \\
84.20 \pm 1.31\end{array}$ \\
\hline \multicolumn{5}{|c|}{$\%$ Control reoxygenation $(2 \mathrm{~min})$} \\
\hline $\begin{array}{r}6 \\
25\end{array}$ & $\begin{array}{l}9 \\
9\end{array}$ & $\begin{array}{l}76.32 \pm 5.15 \\
81.79 \pm 3.29\end{array}$ & $\begin{array}{l}70.02 \pm 4.55 \\
74.23 \pm 2.10\end{array}$ & $\begin{array}{l}113.0 \pm 1.97^{*} \\
121.4 \pm 2.93\end{array}$ \\
\hline
\end{tabular}

${ }^{*} P<0.05$ vs. 25 mo.

$\ddagger P<0.01$ vs. $25 \mathrm{mo}$.

storage to releasing sites. The fact that $\mathrm{CD}$ is prolonged in aged myocardium indicates that the delay occurs in the removal of calcium from the contractile proteins themselves. This sequestration of calcium from the contractile proteins is thought to be mainly a function of the sarcoplasmic reticulum, and delayed sequestration in the aged myocardium, therefore, could result from either tighter binding of calcium to the contractile proteins or to a slower calcium sequestering mechanism.

In summary, we have demonstrated that $C D$ is prolonged in aged myocardium and that this prolongation cannot be explained solely by age changes in visco-elastic properties but must reflect a prolonged active state. Although catecholamines are thought to enhance calcium sequestration (36) and although myocardial tissue catecholamine levels are decreased with age, it appears that slow removal of calcium from the contractile proteins, independent of myocardial catecholamine content, is at least in part responsible for the increased duration of active state in aged myocardium.

\section{ACKNOWLEDGMENTS}

The authors wish to thank Drs. E. Neil Moore and Joseph Spear for their advice and for the use of their laboratory to conduct the microelectrode studies. The technical assistance of Mrs. Elsie Beard and Mr. Ralph Ianuzzi is also gratefully acknowledged.

This work was supported in part by National Heart and Lung Institute Grant no. 16076-01 and U. S. Public Health Service Grant no. HL-15565.

\section{REFERENCES}

1. Weisfeldt, M. L., W. A. Loeven, and N. W. Shock. 1971. Resting and active mechanical properties of trabeculae carneae from aged male rats. Am. J. Physiol. 220: 1921-1927.

2. Alpert, N. R., H. H. Gale, and N. Taylor. 1967. The effect of age on contractile protein ATPase activity and the velocity of shortening. In Factors Influencing Myocardial Contractility. R. D. Tanz, F. Kavaler, and J. Roberts, editors. Academic Press, Inc., New York. 127-133.
3. Grodner, A. S., P. E. Pool, and E. Braunwald. 1970. Influence of age on the mechanics of rat cardiac muscle. Circulation. Suppl. III. 42 : 115. (Abstr.)

4. Harrison, T. R., K. Dixon, R. O. Russell, Jr., P. S. Bidwai, and H. N. Coleman. 1964. The relation of age to the duration of contraction, ejection, and relaxation of the normal human heart. Am. Heart J. 67: 189-199.

5. Gey, K. F., W. P. Burkard, and A. Pletscher. 1965. Variation of the norepinephrine metabolism of the rat heart with age. Gerontologia. 11: 1-11.

6. Frolkis, V. V., V. V. Bezrukov, L. N. Bogatskaya, N. S. Verkhratsky, V. P. Zamostian, V. G. Shevtchuk, and I. V. Shtchegoleva. 1970. Catecholamines in the metabolism and functions regulation in aging. Gerontologia. 16: 129-140.

7. Buccino, R. A., E. H. Sonnenblick, J. F. Spann, Jr., W. F. Friedman, and E. Braunwald. 1967. Interactions between changes in the intensity and duration of the active state in the characterization of inotropic stimuli on heart muscle. Circ. Res. 21: 857-867.

8. Hoffman, B. F., and J. J. Kelly, Jr. 1959. Effects of rate and rhythm on contraction of rat papillary muscle. Am. J. Physiol. 197: 1199-1204.

9. Lee, S. L., G. W. Mainwood, and B. Korecky. 1970. The electrical and mechanical response of rat papillary muscle to paired pulse stimulation. Can. J. Physiol. Pharmacol. 48: 216-225.

10. Tyberg, J. V., L. A. Yeatman, W. W. Parmley, C. W. Urschel, and E. H. Sonnenblick. 1970. Effects of hypoxia on mechanics of cardiac contraction. Am. J. Physiol. 218 : 1780-1788.

11. Tyberg, J. V., W. W. Parmley, and E. Sonnenblick. 1969. In-vitro studies of myocardial asynchrony and regional hypoxia. Circ. Res. 25: 569-579.

12. Brooks, W. W., B. Sturckow, and O. H. L. Bing. 1973. Electromechanical changes during myocardial hypoxia and reoxygenation. Temporal correlates. Circulation. Suppl. IV. 48: 19. (Abstr.)

13. Schlettwein-Gsell, D. 1970. Survival curves of an old age rat colony. Gerontologia. 16: 111-115.

14. Rothbaum, D. A., D. J. Shaw, C. S. Angell, and N. W. Shock. 1973. Cardiac performance in the unanesthetized senescent male rat. J. Gerontol. 28: 287-292.

15. Shreiner, D. P., M. L. Weisfeldt, and N. W. Shock. 1969. Effects of age, sex, and breeding status on the rat heart. Am. J. Physiol. 217: 176-180.

16. Lee, J. C., L. M. Karpeles, and S. E. Downing. 1972. Age-related changes of cardiac performance in male rats. Am. J. Physiol. 222 : 432.

17. Weisfeldt, M. L., J. R. Wright, D. P. Shreiner, E. Lakatta, and N. W. Shock. 1971. Coronary flow and oxygen extraction in the perfused heart of senescent male rats. J. Appl. Physiol. 30: 44-49.

18. Umbreit, W. W., R. H. Burris, and J. F. Stauffer. 1945. Manometric Techniques and Related Methods for the Study of Tissue Metabolism. Burgess Publishing Company, Minneapolis. 194.

19. Kelly, J. J., Jr., and B. F. Hoffman. 1960. Mechanical activity of rat papillary muscle. Am. J. Physiol. 199: $157-162$.

20. Koch-Weser, J. 1966. Potentiation of myocardial contractility by continual premature extra-activations. Circ. Res. 18: 330-343.

21. Hoffman, B. F., C. Y. Kao, and E. E. Suckling. 1957. Refractoriness in cardiac muscle. Am. J. Physiol. 190: 473-482. 
22. Roberts, J. 1974. Effect of age on cardiac pacemakers and their reactivity to drugs. Fed. Proc. 33: 459. (Abstr.)

23. Von Euler, U. S., and F. Lishajko. 1961. Improved technique for fluorometric estimation of catecholamines. Acta Physiol. Scand. 51: 348-356.

24. Snedecor, G. W. 1956. Statistical Methods Applied to Experiments in Agriculture and Biology. Iowa State College Press, Ames. 5th edition.

25. Henderson, A. H., W. W. Parmley, and E. H. Sonnenblick. 1971. The series elasticity of heart muscle during hypoxia. Cardiovasc. Res. 5: 10-14.

26. Templeton, G. H., R. C. Adcock, and J. T. Willerson. 1973. Influence of hypoxia on isolated papillary muscle stiffness and its elastic and viscous components. Circulation Suppl. IV. 48: 67. (Abstr.)

27. Penna, M., F. Linares, and L. Cáceres. 1965. Mechanism for cardiac stimulation during hypoxia. Am. J. Physiol. 208: 1237-1242.

28. Goldstein, R. E., J. S. Borer, and S. E. Epstein. 1972. Augmentation of contractility following acute ischemia in isolated supported heart. Am. J. Cardiol. 29: 265. (Abstr.)

29. Penn, R. G. 1970. The effect of age, species, and adrenaline on the recovery of isolated atria from anoxia. Br. J. Pharmacol. 39: 309-316.
30. Penn, R. G. 1965. Some factors influencing the recovery of isolated myocardium from acute anoxia. $\mathrm{Br} . J$. Pharmacol. Chemother. 24: 253-265.

31. Parmley, W. W., B. Rabinowitz, L. Chuck, G. Bonorris, and J. P. Katz. 1972. Comparative effects of sotalol and propranolol on contractility of papillary muscles and adenyl cyclase activity of myocardial extracts of cat. J. Clin. Pharmacol. 12: 127-135.

32. Nayler, W. G., J. Stone, V. Carson, I. McInnes, V. Mack, and T. E. Lowe. 1969. The effect of beta adrenergic antagonists on cardiac contractions, myofibrillar ATPase activity, high-energy phosphate stores, and lipid-facilitated transport of calcium ions. J. Pharmacol. Exp. Ther. 165: 225-233.

33. Langer, G. A. 1973. Heart: excitation-contraction coupling. Annu. Rev. Physiol. 35: 55-86.

34. Wood, E. H., R. L. Heppner, and S. Weidmann. 1969. Inotropic effects of electric currents. Circ. Res. 24: 409-445.

35. Tritthart, H., R. Kaufmann, H. P. Volkmer, R. Bayer, and $\mathrm{H}$. Krause. 1973. Ca-movement controlling myocardial contractility I. Pflügers Arch. Eur. J. Physiol. 338 : 207-231.

36. Katz, A. M., and D. Repke. 1973. Calcium-membrane interactions in the myocardium: effects of ouabain epinephrine, and $3^{\prime}, 5^{\prime}$ cyclic adenosine monophosphate. Am. J. Cardiol. 31 : 193-201. 